\title{
¿EXISTE ASIGNACIÓN Y MARCA DE CASO EN LOS COMPUESTOS NOMINALES DE VERBO+NOMBRE?
}

El desarrollo experimentado por la investigación gramatical en los últimos años se ha producido gracias a la aplicación del mismo método teórico tanto para la descripción sintáctica como para la morfológica ${ }^{1}$, lo que no ha hecho más que confirmar lo acertado de las imbricaciones entre disciplinas distintas para favorecer el avance científico ${ }^{2}$. Esto significa que el sistema de re-

${ }^{1}$ Si bien esto no niega la consideración de la morfología como un componente autónomo de la gramática dentro de la gramática generativa transformacional que conlleva, como señala PenA, unos "objetivos, reglas y principios específicos que rigen tales reglas: los procesos de formación de palabras se dan en el componente léxico y las reglas de formación de palabras (RFP) son específicas de dicho componente. La razón para deslindar un componente morfológico dentro de la gramática de una lengua está en que la competencia del hablante le permite no sólo comprender y emplear palabras de su lengua, sino también tener conocimientos acerca de su estructura y de su significado en consonancia con su estructura" ("Formación de palabras, gramática y diccionario", RLex, 1, 1994-95, p. 163). Este desarrollo gramatical que dota de autonomía a la morfología es el resultado de las propuestas formuladas por Halle ("Prolegomena to a theory of wordformation", LI, 22, 1973, 141-159) y ARONOFF (Word formation in Generative Grammar, The MIT Press, Cambridge, 1976) -y a partir de ahí SELkiRk (The syntax of word, The MIT Press, Cambridge, 1982) y SCALISE (Morfología generativa, trad. J. Pazó y adapt. al esp. S. Varela, Alianza Universidad, Madrid, 1987 [1984]) - a raíz de las críticas a la propuesta transformacional de explicar la palabra compleja como resultado de alterar una estructura frástica u oracional subyacente.

2 De ahí la importancia de las palabras con que Violeta Demonte abre su Teoría sintáctica: de las estructuras a la rección, Síntesis, Madrid, 1991, p. 9: "la observación penetrante, la indagación sistemática en aspectos aparentemente triviales de los fenómenos naturales o sociales ha llevado en algunas ocasiones a dar pasos de gigante en el desarrollo del conocimiento científico; lo elemental puede tener a veces causas intrincadas y reveladoras. Pero 
glas que se ha utilizado para explicar la estructura de una palabra no es más que una extrapolación del sistema de reglas utilizado para dar cuenta de la estructura sintagmática, dada la condición de la palabra como unidad transversal entre la morfología y la sintaxis ${ }^{3}$. Por ello, se aplica la noción de estructura tanto a la oración como a la palabra, lo que permite explicar adecuadamente la situación en que se encuentran los elementos que conforman estas dos unidades gramaticales, utilizando para su análisis los mismos principios teóricos, a pesar de la consideración de la morfología derivativa como resultado de una operación léxica, no sintáctica, pero con una estructura interna en la que sus constituyentes también están organizados en distintos niveles jerárquicos ${ }^{4}$. Esto es, hay una gramática para la formación de las oraciones, del mismo modo que hay una gramática para la formación de las palabras; si puede establecerse un paralelismo entre la oración - o el sintagma-y la palabra, cuando ésta es compleja, dicha conexión es todavía más

las consecuencias de estos pasos han podido ser aún más trascendentes cuando una disciplina ha hecho suya idea o nociones de otra zona del saber supuestamente independiente de ella".

${ }^{3}$ En este sentido Piera y Varela afirman que "parece que los dominios de una y otra están bien delimitados y que el objeto de estudio de cada una de ellas abarca entidades claramente diferenciadas. No obstante, en nuestra lengua, al igual que en otras, se dan diferentes fenómenos léxico-gramaticales que conciernen tanto a los objetivos de la sintaxis como a los de la morfología y se encuentran en ellas ciertas entidades lingüísticas que participan de las características propias de las entidades morfológicas, la palabra y el morfema, a la vez que de las sintácticas, el sintagma y la oración" ("Relaciones entre morfología y sintaxis", en Gramática descriptiva de la lengua española, dirs. I. Bosque y V. Demonte, Espasa Calpe, Madrid, 1999, t. 3, p. 4369).

${ }^{4}$ Idea defendida por SELKIRK (op. cit.) quien ha aplicado la teoría sintáctica de la X-barra a las reglas de formación de palabras, explicando la unión de los constituyentes por medio de una estructura jerárquica y relacionando afijos y bases de la misma manera que en la estructura sintagmática o frástica: en particular, en todo lo referente a las semejanzas entre la estructura sintáctica y la estructura de la palabra, se ha afirmado que las teorías acerca de la primera pueden ser aplicables a la segunda. No faltan, sin embargo, críticas a la aplicación de la teoría de la X-barra en el análisis morfológico, como hace SCALISE, aunque no deja de admitir que "parece que la teoría de la X-con barra se puede aplicar con resultados interesantes para expresar ciertas analogías entre principios que rigen la construcción sintagmática y los que determinan la formación de palabras dentro de la morfología, al menos por lo que se refiere a los compuestos" (op. cit., pp. 210-216). 
estrecha cuando nos fijamos en los compuestos nominales y, en particular, en un tipo de formaciones como aquellas en las que intervienen un verbo más un nombre, que bien pueden considerarse formaciones intermedias entre la sintaxis y la morfología, pues en ellas la consideración de una posible subyacencia o estructura profunda de carácter sintagmático puede aclarar la naturaleza de las relaciones que contraen los constituyentes, al tiempo que refleja la herencia de la estructura argumental ${ }^{5}$. Es-

${ }^{5}$ A pesar de que las explicaciones para determinar la estructura interna de estos compuestos no defienden hoy la existencia de una estructura frástica subyacente, sobre todo a partir de la hipótesis lexicalista chomskyana de 1970. Sin embargo, es en su correlato con una estructura oracional donde reside el punto de partida para la creación, por parte de los hablantes, de compuestos nominales de este tipo. El esquema morfológico que lleva a la formación de estos compuestos es muy productivo en español, gracias a las pocas restricciones con que cuenta y a su transparencia semántica y regular, así como a su correlato con una estructura sintagmática con los mismos elementos. A pesar de ello, la explicación transformacional hizo aguas y "pronto se reconoció la dificultad de basar la explicación del léxico derivado en el mecanismo transformacional: las similitudes entre pieza léxica simple y derivada no eran totales desde el punto de vista sintáctico, la relación distaba mucho de ser sistemática y productiva y el número y complejidad de transformaciones que había que postular si se pretendía generar todo el léxico derivado mediante este mecanismo complicaba en exceso la gramática, hasta el punto de hacerla inadecuada como modelo de explicación de la competencia del hablante nativo" (VARELA, Fundamentos de morfología, Síntesis, Madrid, 1992, p. 139). Y en este sentido Lang expone también el desarrollo experimentado por el análisis morfológico centrado en la explicación transformacional "siguiendo los postulados de la teoría sintáctica postchomskiana, los procedimientos implicados en la formación de palabras se concibieron como análogos a aquellos implicados en la formación de nuevas oraciones. La forma de las palabras complejas se analizaba como si respondiera a una estructura sintáctica, considerando tan sólo el derivado o el compuesto como una mera representación superficial de ella, una especie de abreviamiento de carácter gráfico" hasta llegar a observar las limitaciones e insuficiencias de dicho procedimiento: "este enfoque puede resultar engañoso, porque analiza todos los elementos en términos de estructura profunda y, además, manifiesta una tendencia a destacar las relaciones oracionales entre verbo y nombre que fascinaron a los lingüistas postchomskianos. Por ejemplo, suele no reparar en otros tipos de relaciones sintácticas que se dan en la formación de palabra, tales como las estructuras nombre-nombre (antenista) o adjetivo-nombre ( fragilidad) y adolece de una insuficiente consideración del componente sintáctico, que caracteriza muchas derivaciones, como se (de)muestra en los siguientes ejemplos: chupalámparas *persona o aparato que chupa lámparas" (Formación de palabras en español. Morfología derivativa productiva en el léxico moderno, trad. A. Miranda Poza, Cátedra, Madrid, 1992, 
to se compadece bien con la idea de que la composición entraña una combinación sintáctica de elementos léxicos en el nivel de la palabra; de ahí lo oportuno de afirmaciones como la que hacen Piera y Varela cuando señalan que

aparte del hecho notorio de que son frecuentes las formaciones léxicas con estructura morfológica compleja que proceden, diacrónicamente, de combinaciones sintácticas, de modo que los sintagmas se vuelven palabras y estas, a su vez, pueden convertirse en afijos, hay aspectos generales de la gramática en los que la interacción de la morfología y la sintaxis es evidente ${ }^{6}$.

Lo que me propongo hacer en este trabajo es analizar la configuración interna de los compuestos nominales del tipo verbo + nombre, ahondando en las explicaciones que se han ofrecido a propósito de la naturaleza del primer elemento del compuesto e introduciendo en la controversia acerca de su caracterización (centrada en determinar si es una forma personal verbal, un tema verbal, un nombre deverbal, etc.; elección que Alvar Ezquerra considera arriesgada porque ninguna de las

p. 15). Aunque Lang no niega que "la consideración de la posible subyacencia o estructura profunda implícita en una estructura léxica compleja puede aclarar la naturaleza de las relaciones entre los constituyentes: trotar + mundo $\longrightarrow$ trotamundos, lavar + vajilla $\longrightarrow$ lavavajillas" (p. 17). Con esta afirmación acerca de las relaciones entre morfología y sintaxis no se defiende aquí la idea de una transformación como punto de partida para la formación de estos compuestos nominales, procedimiento que ha sido desestimado y superado ya, como refleja gran parte de la bibliografía ocupada de este tema (puede verse, por ejemplo, el resumen que ofrece SCALISE, op. cit., pp. 24-29), aunque algunos estudiosos todavía defiendan, como apunta LANG (op. cit., p. 85), la interacción entre los procesos derivativos y la sintaxis, en el sentido de que el análisis sintáctico de las palabras complejas puede explicar el funcionamiento de los mecanismos de formación. Sólo se pretende mostrar aquí la semejanza en el mantenimiento de la misma estructura argumental o temática entre una estructura oracional verbo+objeto y una palabra compleja del tipo limpiabotas en la que se da el mismo tipo sintáctico, el más productivo, por cierto, de todos los que pueden señalarse dentro de los compuestos de verbo+nombre. Claro que no hay que negar que la consideración de la posible subyacencia o estructura profunda implícita en una estructura léxica compleja, como la que abordamos aquí, puede aclarar también la naturaleza de las relaciones entre los constituyentes, algo que es activado por parte de los hablantes para crear hoy este tipo de unidades morfológicas.

6 Art. cit., p. 4369. Las cursivas son mías. 
propuestas excluye a las demás ${ }^{7}$ ) las explicaciones que se derivan de la aplicación de la teoría del caso, surgida en el marco teórico del modelo gramatical de Principios y Parámetros ${ }^{8}$, con el fin de responder a la pregunta que da título a este trabajo: si existe o no asignación y marca de caso en este tipo de compuestos. De acuerdo con dicha teoría, en la estructura-S, los elementos que conforman una oración tienen una disposición lineal y estructural determinada por la asignación de caso que efectúa un elemento rector sobre su regido ${ }^{9}$. Parece que esta si-

${ }^{7}$ Si bien en su opinión "debemos admitir que los compuestos endocéntri$\cos y$, por tanto, los que poseen en su interior la forma verbal bajo el presente de indicativo, son mayoría en la lengua actual" ("De nuevo sobre los compuestos de verbo + sustantivo", II Simposio Internacional de Lengua española, ed. M. Alvar, Excmo. Cabildo Insular de Gran Canaria, Las Palmas, 1984, p. 96).

8 Este modelo teórico de Principios y Parámetros es la tercera fase de la gramática chomskyana. Después del alto grado de formalismo e interés por las propiedades matemáticas de los formalismos gramaticales expuestos en Estructuras sintácticas y tras la teoría estándar de Aspectos, en la que se introducía un componente semántico y se concebía el lenguaje como un sistema de conexiones entre significados y sonidos, surgió la Teoría de Principios y Parámetros, también llamada de Rección y Ligamiento. Dicha teoría representó la culminación del interés de Chomsky por la adecuación explicativa que intentaba responder a la pregunta de cómo se aprende una lengua. Como resume Wasow en el epílogo al libro de SELls estas tres fases describen "el curso sostenido y único en que se ha desarrollado la teorización sintáctica durante los últimos treinta años en que el rigor formal y la atención a los detalles gramaticales dio paso poco a poco a la predilección por la gramática universal y las cuestiones teóricas más trascendentales" (Teorías sintácticas actuales, trad. R. Cerdá, Teide, Barcelona, 1985, p. 191).

${ }^{9}$ Demonte señala la existencia de unas condiciones que restringen las estructuras-S: "en esencia, éstas tratan sobre relaciones entre pares de elementos de los cuales uno es, en algún sentido, jerárquicamente superior al otro, siendo necesario asimismo que esa relación jerárquica se satisfaga en un dominio determinado. Con otras palabras, las nociones de rección y localidad son pieza clave de los fenómenos de asignación de caso, ligamiento, controle identificación de categorías vacías" (op. cit., p. 135). Y más adelante precisa que "la teoría lingüística ha hecho progresos considerables en el conocimiento de estos fenómenos de dependencia o interdependencia estructural y ha elaborado, tras extensos análisis teóricos y empíricos, dos nociones (o principios estructurales) que parecen muy fructíferas para la caracterización de esas dependencias: una es la más abarcadora de mando-c (mando de constituyentes), otra es la más específica de rección, de la cual la anterior es una subparte" (p. 138). Y sobre el concepto de rección explica que "el principio de rección es meramente una relativización de la relación de mando-c a dominios locales muy específicos, en particular, al de las relaciones entre los núcleos léxicos de los sintagmas y los elementos que coaparecen con ellos dentro de la proyección máxima de la que 
tuación habría de darse también entre estos dos elementos del compuesto para explicar la buena formación de dicho compuesto, si bien es cierto que las similitudes que se pueden establecer entre la oración y la palabra tienen el límite que impone la consideración de la palabra compleja como átomo sintáctico, con integridad léxica, en el que no pueden intervenir cualesquiera de los principios de análisis de la estructura sintagmáti$\mathrm{ca}^{10}$. Por ello Piera y Varela afirman que

si bien es posible recurrir a la sintaxis oracional para describir determinadas relaciones de dependencia dentro de la palabra, ello no implica que las formaciones léxicas tengan estatuto sintáctico. La constatación de que una pieza morfológica compleja muestra una 'sintaxis interna' se resume en el hecho de que las relaciones estructurales que se dan en su interior están sometidas a principios bien establecidos de la gramática, los cuales pueden ser definidos en términos sintácticos o estructurales. Hay que tener presente, por otra parte, que ciertas propiedades distribucionales que caracterizan a las palabras complejas son privativas de la morfología ${ }^{11}$.

Ahora bien, las posibilidades actuales para la creación de compuestos del tipo verbo + nombre, a partir de estructuras verbales en las que aparece un objeto o tema, regido o seleccionado por el verbo, permiten reanalizar la naturaleza de este tipo de compuestos con el objeto de profundizar en la explicación más extendida en la actualidad, en virtud de la cual el primer elemento del compuesto es considerado un nombre deverbal, insistiendo en el origen verbal del primer elemento y en las implicaciones que ello conlleva; al mismo tiempo, la facilidad para su creación permite que su interpretación semántica se

son ejes, los elementos que por razones semánticas o meramente formales aquéllos «exigen» o «rigen»" (p. 137).

${ }^{10}$ Esta particularidad de la palabra como átomo sintáctico aparece en Сномsку (“Observaciones sobre la nominalización”, Sintáctica y semántica en la gramática generativa, introd., notas y apéndices C. Pelegrín Otero, Siglo XXI, Madrid, 1979 [1970], pp. 25-74) y postula que las operaciones sintácticas no pueden acceder a la estructura interna creada por operaciones morfológicas; esto es, como señala VARELA (Fundamentos de morfología, p. 37) son opacas a la sintaxis.

11 Art. cit., p. 4381. 
pueda derivar - a pesar de que las conclusiones a que se ha llegado desde un análisis estrictamente formal no apoyan esta hipótesis-de las partes que lo componen -es decir que sea posible una interpretación composicional parcial del significado, dada su transparencia semántica ${ }^{12}-$ y de la relación que las partes entablan entre sí. Pero antes de abordar la repercusión que tiene la aplicación de la teoría del caso en la determinación de la estructura interna de los compuestos de $\mathrm{V}+\mathrm{N}$, expondré brevemente cuál es el contenido de la teoría y los mecanismos que llevan a su aplicación.

\section{PRINCIPIO DE ASIGNACIÓN DE CASO Y MARCAS DE CASO}

El surgimiento de la teoría de los Principios y Parámetros en la década de los años ochenta supuso la aparición del desarrollo más generalizado de la gramática generativa ${ }^{13}$. Este modelo de descripción gramatical se articula en torno a la existencia de va-

12 Lo que no es posible en todos los compuestos nominales de verbo +nombre: no sucede en formaciones como cascarrabias en las que, como apunta VAL Álvaro ("La composición", en Gramática descriptiva de la lengua española, t. 3, p. 4766), intervienen el mismo tipo de mecanismos tropológicos de denotación que en gallocresta o salipez: gallocresta 'planta medicinal de hojas parecidas a la cresta de un gallo'; salipez 'tipo de roca blanca con manchas negras'. Hay que señalar también, como hace Almela a propósito del origen del compuesto, que "no siempre está claro qué unidad lingüística se halla en el origen del compuesto, ni siquiera si existe tal origen. En las contadas ocasiones en que pudiera haber acuerdo sobre tal origen, ¿no se le estaría confundiendo con una paráfrasis a posteriori?" (Procedimientos de formación de palabras en español, Ariel, Barcelona, 1999, p. 121). Por ello, como concluye LANG, "se producen frecuentes modificaciones semánticas entre los constituyentes y el derivado resultante, con el consiguiente oscurecimiento de la motivación semántica... Con el paso del tiempo las palabras pueden adquirir significados impredecibles que no se derivan directamente a partir del que poseen sus componentes" (op. cit., p. 71).

${ }^{13}$ Este modelo teórico se ocupa de la facultad lingüística y de la gramática y se articula en torno a la idea de que el sistema lingüístico consta de un conjunto restringido de principios generales que dan cuenta de las propiedades y leyes del lenguaje y que están asociados a un conjunto igualmente restringido de parámetros que permiten, según la posición que tomen, cierta variación interlingüística. Las obras fundamentales en las que se explica el modelo son Chомsкy, Lectures on government and binding, Foris, Dordrecht, 1981; y CHOMsky y LASNiк, "Principles and parameters theory", en Syntax: An international handbook of contemporary research, eds. J. Jacobs et al., De Gruyter, Berlin, 1991. 
rios módulos o conjuntos de principios que regulan la buena formación de una oración; con ello lo que se persigue es dividir nuestro conocimiento del sistema en componentes relativamente independientes, pero conectados entre sí. Dentro de esos módulos, encargados fundamentalmente de explicar las relaciones formales y semánticas entre los miembros que conforman la estructura sintagmática, se encuentra, en el módulo sintáctico, la teoría del Caso. Esta teoría es la encargada de regular la aparición o distribución de los sintagmas nominales, obligatorios o argumentales, en la cadena oracional por medio de una marca de función casual que recibe el nombre de caso y cuya función es similar a la existente en lenguas que disponen de esa marca morfológica ${ }^{14}$. El principio básico de esta teoría señala que todo sintagma nominal debe recibir una marca casual del elemento que lo rige, lo que explica la agramaticalidad de ciertas oraciones ${ }^{15}$ : en español, por ejemplo, un participante que funcione como objeto directo sólo podrá estar separado del verbo del que depende por otro participante si lleva una marca de caso explícita; en caso contrario deberá permanecer en una posición adyacente o subyacente al verbo ${ }^{16}$, lo que hace que co-

${ }^{14}$ Dicha marca, cuya existencia conocemos en lenguas como el latín, da lugar a la variación en el sustantivo, de acuerdo con la función que éste desempeñe en la oración. En el modelo de Principios y Parámetros todo SN debe llevar caso asignado, salvo algunas excepciones posibles de categoría vacía. La falta de caso tiene como resultado la existencia de una oración agramatical, al mismo tiempo que la duplicación de caso también sería agramatical. Por esta razón, SELls explica que "el filtro de caso es como el criterio temático en cuanto establece que tener dos casos es tan inválido como no tener ninguno. Hay, por lo demás, una gran similitud en la actuación del criterio q y el filtro de caso, hasta el punto de que en trabajos más recientes (cf. Chомsкy, Knowledge of language: Its nature, origins, and use, The MIT Press, Cambridge, 1984, siguiendo las pautas de Rección y Ligamiento) se ha revisado el criterio q con el fin de incluirlo en el filtro de caso" (op. cit., p. 52).

${ }^{15}$ Cuando en una oración un sintagma nominal explícito no tenga asignado un caso, resultará una secuencia anómala porque se incumplirá el filtro de caso. Sells (loc. cit.) explica el filtro de caso, que se aplica en la estructura $\mathrm{S}$, diciendo que un SN es agramatical si el SN tiene contenido fonético-esto es, tiene una realización física, por oposición a la categoría vacía- y, en cambio, carece de caso.

${ }^{16}$ En estos movimientos relacionados con el orden de palabras interesa, para mantener las restricciones que impone la teoría del límite, que se preserve la adyacencia o por lo menos la subyacencia, según se trate de unas lenguas u otras. En inglés es obligatoria la adyacencia entre el verbo y su complemento directo porque no puede interponerse nada entre el asignador de caso y su 
bre importancia, en el marco de la teoría del caso, la existencia de un orden lineal -que dé cuenta del predominio en español del orden $\mathrm{SVO}^{17}$ - al lado de un orden jerárquico, que se viene bien con la existencia previa de una marca de caso ${ }^{18}$.

La existencia de caso y su asignación por parte de una determinada categoría gramatical es el modo de reconocer formalmente la relación que existe entre un elemento regido y su rector. Para marcar la relación de dependencia se recurre al $c a-$

asignado; de lo contrario, el resultado sería agramatical (como se ve en *John read in the bed the novels). En cambio, en español no se da esta restricción tan fuerte, aunque sí es necesario que se dé por lo menos la subyacencia, fenómeno consistente en que ninguna aplicación de desplazamiento de a puede cruzar más de un nudo limítrofe (claro que se puede recurrir a la adyacencia que parece evitar los casos de ambigüedad estructural que se dan en la estructura S, y no en la FL donde siempre habría dos representaciones estructurales, caracterizada una de ellas por la adjunción de los argumentos a aquellos elementos que los rigen).

17 BosQue señala que "las lenguas que disponen de gran número de casos para identificar los complementos de los núcleos son aquellas en las que las posiciones sintácticas son libres, o dicho de otra forma, aquellas en las que la adyacencia no es una marca de función apropiada o suficiente. Los complementos necesitan, pues, diferentes marcas de función que se ajustan a la estructura de cada lengua. La forma en la que se producen estas marcas de función (que en la gramática generativa reciente se agrupan bajo el término de Caso abstracto) condicionan buena parte de su sintaxis" (Las categorías gramaticales, Síntesis, Madrid, 1989, p. 68). Esto hace que la posición sea un procedimiento para legitimar o reconocer complementos, lo que significa que cobre importancia el orden en que aparecen las unidades de análisis.

18 Pinker señala que "en las lenguas que emplean marcadores de caso para señalizar el significado, un sintagma recargado puede ser desplazado hacia el final de la oración, de tal modo que el oyente pueda digerir el significado de un sintagma tan largo sin necesidad de mantenerlo en la memoria. Incluso una lengua tan tiránica en cuanto al orden de palabras como el inglés ofrece a sus hablantes construcciones alternativas en las que invierte el orden de los sintagmas. Todo escritor considerado debe hacer uso de estas construcciones, dejando lo más pesado para el final y aligerando el principio de la oración" (El instinto del lenguaje, trad. J. M. Igoa González, Alianza Editorial, Madrid, 1999 [1994], p. 222). Precisamente en la importancia que tiene el orden lineal junto con el jerárquico reside la razón por la que surgen oraciones ambiguas o anómalas en todas las lenguas. Es el caso de la siguiente secuencia que tomo de Pinker: Joaquín dijo que Santiago hará sus deberes ayer, en la que la anomalía surge porque "normalmente es preferible empaquetar nuevas palabras dentro del sintagma incompleto que se está analizando, a cerrar el sintagma y colocar las palabras que vayan llegando en otro sintagma pendiente de una rama superior del árbol” (p. 236), lo que explica la tendencia a conjugar orden jerárquico y orden lineal. 
so, que puede ser desempeñado por afijos, formas léxicas o posiciones sintácticas, y que la lengua emplea para distinguir los diversos papeles que desempeñan los participantes en un determinado suceso o estado; papeles tales como sujeto, objeto directo, objeto indirecto, así como los objetos introducidos por las distintas clases de preposiciones. Esa marca de caso puede tener o no concreción morfológica; de modo que en las lenguas que disponen de flexión de caso se habla de caso morfológi$c o$, mientras que en aquellas que carecen de tal posibilidad $\mathrm{y}$, por tanto, la existencia de caso es abstracta, se habla de caso abstracto. Cuando esto sucede, las diferencias entre las funciones sintácticas se manifiestan también por medio de marcas, aunque no sean tan visibles como las de otras lenguas: en español no existe caso morfológico en los sustantivos, pero la aparición de éstos en la oración también está sujeta al mismo principio funcional-casual, regulador de la aparición de los elementos nominales en las leguas dotadas de caso morfológico.

La conclusión que podemos extraer de esta breve exposición de la teoría del caso y de los elementos encargados de que se cumpla, es que las oraciones que producimos deben mantenerse siempre bajo el dominio de verbos y preposiciones: los sintagmas no pueden aparecer en la posición que les venga en gana dentro del SV, tienen que someterse al papel que éste les asigne y llevar en todo momento el distintivo de la función que se les ha encomendado ${ }^{19}$. La existencia de una teoría de caso y

${ }^{19}$ Los elementos capaces de asignar caso son aquellas categorías gramaticales que llevan el rasgo [-N]. Esta descripción de las categorías, como resultado de la combinación de los rasgos categoriales $\mathrm{N}$ y V, ha surgido en el análisis de teoría de X-barra, que tiene su origen en CHомsкy ("Observaciones sobre la nominalización") y que se ha desarrollado posteriormente en Jackendoff, $X$ ' syntax: A study of phrase structure, The MIT Press, Cambridge, 1977, у Сномsку, Lectures on government and binding. De acuerdo con esta teoría, las categorías léxicas que pueden asignar caso son únicamente el verbo $[+\mathrm{V},-\mathrm{N}]$ y la preposición $[-\mathrm{V},-\mathrm{N}]$, lo que explica la agramaticalidad de expresiones como presidente el Gobierno o asustado el lobo, aun cuando sea posible dotarlas de una cierta interpretación. Fernández Lagunilla y ANula Rebollo (Sintaxis y cognición. Introducción al conocimiento, procesamiento y los déficits sintácticos, Síntesis, Madrid, 1995, p. 167) explican que sólo el verbo y la preposición son asignadores "directos" de caso. Y hay que precisar que sólo el verbo transitivo de la voz activa, pues en la voz pasiva es necesario que el SN objeto sufra un desplazamiento A de una posición temática sin caso a una posición no temática capaz de asignarle caso; y esa posición es la de sujeto. Y no todos los verbos pueden asignar caso acusativo al SN que los acompaña. 
los principios existentes para la asignación de caso en español están en consonancia con el hecho de que la estructura de esta lengua sea SVO. A excepción del sujeto, que recibe la asignación de caso de la flexión verbal ${ }^{20}$, las semejanzas que pueden establecerse entre el SV y otro tipo de sintagmas - SN, SA o SPen los que aparecen los mismos elementos -núcleo, adyacentes, modificadores y especificadores-, así como la posición que ocupa cada uno de esos elementos en el interior del sintagma, explican el procedimiento que se sigue para la asignación de caso. Pero esa necesidad de asignar caso y el mecanismo para hacerlo está ligado también a la asignación de papel temático: de hecho, en español son únicamente los verbos y las preposiciones los que asignan tanto papel temático como caso; en lo que respecta a las preposiciones, esto encuentra una explicación en el hecho de que sea la preposición el elemento que dota de valor temático a los argumentos no seleccionados semánticamente, esto es, a los adjuntos. Por ello, podría pensarse que las preposiciones se recogen en el lexicón con una estructura argumental, similar a la verbal. Sin embargo, aceptar esta postura no está libre de problemas ${ }^{21}$, razón por la cual parece más acertado afirmar que la función de las preposiciones es mediar en la proyección de un determinado papel, ser las transmisoras de él, pues requieren la presencia previa de un verbo que posea dicho papel temático. Esa función de mediación también la realizan las preposiciones al unir un modificador a un núcleo en el interior de un sintagma nominal, es decir al asignar caso a un nombre ${ }^{22}$.

Esto explica la agramaticalidad de secuencias como *Juan salió el coche. La razón estriba en que sólo los verbos transitivos pueden asignar caso acusativo.

${ }^{20}$ Repárese en que la diferencia fundamental que existe entre la posición de sujeto de la oración con verbo conjugado y ese mismo nudo en una construcción de infinitivo, es la ausencia de rección en esta última situación.

${ }^{21}$ Pues como señala Demonte "contrariamente a lo que sucede con los verbos y los adjetivos deverbales, no puede en este caso afirmarse que la proyección de esos papeles temáticos dependa exclusivamente de que las preposiciones tengan especificados, en su correspondiente entrada léxica, un conjunto de papeles temáticos que deban proyectarse necesariamente si ellas se proyectan. De hecho, el papel temático instrumental, comitativo o benefactivo estará asociado al verbo y la preposición en cuestión aparecerá si y sólo si aparece el verbo que así lo determina” (Teoría sintáctica de las..., p. 77).

${ }^{22}$ Alcina y Blecua explican que "para la Gramática de la Academia la preposición es llamada impropiamente parte de la oración puesto que no 


\section{LA MARCA DE CASO EN EL INTERIOR DEL SINTAGMA NOMINAL}

La diferencia existente entre la aplicación de la teoría del caso en el sintagma verbal o la asignación de caso al sujeto por parte de la flexión verbal, y ese mismo procedimiento en el interior de un sintagma nominal, reside en la necesidad de la mediación de una preposición que ligue el núcleo con su modificador, cuando éste sea un nombre (a excepción de los casos de aposición) ${ }^{23}$. Esto explica que sólo sea posible unir dos sustantivos si entre ellos media una preposición, restricción que no se aplica cuando el modificador es un adjetivo; y la función de la preposición no es tanto indicar que una determinada relación sintáctica se está dando, como posibilitar que se dé. En la mayoría de los casos esa función de unión es desempeñada por la preposición $d e$, dada su condición de preposición vacía, carente de significado léxico y capaz de introducir complementos nominales de muy diverso tipo, según explica la gramática tradicional, que distingue entre preposiciones llenas o verdaderas y vacías o falsas ${ }^{24}$.

tiene valor por sí misma en el habla" y sirve para, en estrecho contacto con el nombre, convertirlo en complemento de otro vocablo, de tal manera que la preposición "el entendimiento la concibe como formando un solo concepto mental con dicho nombre, y al expresarlo lo hace como si las dos palabras, es decir, la preposición y el nombre, fuesen una sola" (Gramática española, Ariel, Barcelona, 1975, pp. 826-828). Con una orientación semejante la había entendido Bello al considerarla como modificativo del nombre para convertirlo en complemento mediante el cual expresaba las relaciones posibles entre el nombre y otra palabra. En relación con el nombre, el oficio de la preposición es "anunciarlo, expresando también a veces la especie de relación de que se trata”. En suma, se destacan tres aspectos como característicos: expresan con mayor o menor vaguedad o precisión una relación, y por ello coinciden con los que se han llamado adverbios prepositivos o relacionales; marcan a un nombre o constituyente que haga sus veces y convierten dicho constituyente en complemento de otra palabra, esto es, subordina gramaticalmente el término o constituyente marcado por la preposición a otra palabra que la rige.

${ }^{23}$ Así explica Alarcos que "las preposiciones son unidades dependientes que incrementan a los sustantivos, adjetivos o adverbios como índices explícitos de las funciones que tales palabras cumplen bien en la oración, bien en el grupo nominal" (Gramática de la lengua española, Espasa Calpe, Madrid, 1994, p. 215).

24 Alcina y Blecua señalan que la consideración del significado para explicar el valor de las preposiciones justifica que la gramática tradicional haya establecido la distinción entre preposiciones llenas y vacías: las prepo- 
$\mathrm{Al}$ consultar el tratamiento que ha recibido la preposición de en distintas gramáticas del español, se observa que su caracterización se centra en explicar su falta de autonomía semántica, así como la multitud de valores que puede adoptar. Esto lo hace la RAE al señalar trece usos diferentes para el elemento ${ }^{25}$; por su parte Alcina y Blecua consideran que

la gramática tradicional ha intentado hacer una clasificación de las preposiciones atendiendo al significado. Ha tomado en cuenta necesariamente el hecho de que, mientras unas preposiciones dan cuenta de la relación que expresan cuando se toma en consideración el significado de la palabra regente y del término, en otras basta con la consideración del término para entender la relación. Mientras por toma un significado determinado según la clase de palabra que introduzca - por la calle, por Navidades, por Alfredo, por miedo, por zoquete, etc.- la preposición de sólo alcanza

siciones llenas son las que "se emplean en un reducido número de realizaciones de acuerdo con su significado" y las vacías "aparecen como simples marcas de enlace con múltiples posibilidades de relación cuyo significado es función tanto de la palabra con la que se relacionan como del término que introducen" (op. cit., p. 834). En virtud de esta distinción puede decirse que las preposiciones llenas que materializan un papel temático específico dan lugar a una proyección máxima que bloquea ciertas relaciones estructurales - por eso es agramatical una secuencia, tomada de Demonte (Teoría sintáctica..., p. 79), como * Le regalé un libro a mi prima muy cansada frente a Encontré a mi prima muy cansada-; en cambio, cuando las preposiciones son vacías y no pertenecen al módulo temático no configuran una proyección de sintagma preposicional, que es lo que sucede con los modificadores de núcleos deverbales en sintagmas nominales introducidos por de (claro que no con todos los modificadores como se explica en Demonte, pp. 85-86).

${ }^{25}$ Los valores que señala en el Esbozo (Espasa Calpe, Madrid, 1973, p. 440) son los siguientes: 1) propiedad, posesión o pertenencia; 2) origen o procedencia; 3) modo o manera; 4) materia de que está hecha una cosa; 5) contenido de alguna cosa; 6 ) asunto o materia de que se trata; 7) tiempo en que sucede una cosa; 8 ) uso de una cosa cuando sólo se toma parte de ella; 9) naturaleza, condición o cualidad de personas o cosas; 10) con infinitivos; 11) es a veces nota de ilación o consecuencia; 12) precediendo al numeral uno, una, expresa la rápida ejecución de alguna cosa; 13) colócase entre distintas partes de la oración con expresiones de lástima, queja o amenaza. Por su parte Alarcos explica que "el valor léxico de cada preposición solo se pone de manifiesto y sirve a la información cuando forma parte de un segmento que funcione como adyacente circunstancial (o adyacente oracional). En estas ocasiones es donde las preposiciones se oponen entre sî para denotar sentidos diferentes" (op. cit., p. 221). Para una exposición detallada de los valores que puede adoptar la preposición de, según ALCina y BLEcuA, puede verse op. cit., pp. 938-944. 
su plenitud de significado cuando, además de la palabra que introduce, se considera la palabra con la que se relaciona: el segmento /de toros/ no marca por sí mismo la relación que será una en tarde de toros y otra en hablaron de toros $^{26}$;

y Alarcos quien encuentra en su carencia de significado léxico lo que le permite poder introducir adyacentes muy variados:

la preposición de enlaza un adyacente con el sustantivo nuclear de un grupo nominal, sin que sean pertinentes sus valores léxicos; es un simple índice de la dependencia del sustantivo adyacente respecto del núcleo, y puede por tanto referirse a muy variadas relaciones reales entre los entes denotados ${ }^{27}$;

a diferencia de otras preposiciones que sí están dotadas de significado y que, por tanto, otorgan siempre el mismo papel temáti$\mathrm{CO}^{28}$. De un modo similar Hernanz y Brucart señalan que el SN no puede funcionar como complemento del nombre debido a los requisitos que impone la teoría del caso, en virtud de la cual es necesaria la presencia de la preposición. Sin embargo, la existencia de construcciones como coche cama o curso puente ponen de manifiesto que es posible complementar un núcleo nominal con otro nombre, situación que explican del siguiente modo:

A caballo entre la composición y la complementación nominal, estas formas tienen algunas características especiales. Así, por ejemplo, la categoría de la derecha nunca puede representar proyecciones superiores al núcleo léxico N (es decir que el segundo elemento nominal no puede aparecer dotado de un especificador o de un complemento propio: *coche cama comodísima, *pez dos espadas), lo que hace pensar que se trata más de un procedimiento morfológico limitado por criterios léxicos que de un recurso sintáctico general del español ${ }^{29}$.

26 Ibid., p. 835.

27 Op. cit., p. 220.

${ }^{28}$ Es lo que sucede, por ejemplo, con las preposiciones por o con, a pesar de que Alcina y Blecua las consideran vacías: "aunque falta un criterio suficientemente elaborado para trazar una división objetiva, provisionalmente puede afirmarse que las preposiciones $a, c o n, d e$ y en, y en algunos aspectos por, son vacías, mientras las restantes ante, bajo, contra, desde, entre, hacia, hasta, para, por, según, sin, sobrey tras y las pseudopreposiciones significan por sí mismas o por la naturaleza y carácter del término" (op. cit., p. 835).

29 La sintaxis. Principios teóricos. La oración simple, Crítica, Barcelona, 1987, p. 156. 
Lo mismo sucede en un caso particular de sintagma nominal en el que encontramos secuencias cuyo segundo componente es un nombre propio, como calle Zamora, o en construcciones como casa Pepe, en las que se ha producido la elisión de la preposición. El motivo que puede explicar su elisión es el uso sin preposición en el habla, lo que ha hecho que estos casos se consideren ejemplos de aposición especificativa o adjunta, según explican Alcina y Blecua ${ }^{30}$, con idéntica estructura a la de los compuestos. De este modo resulta normal que se produzca un paso de sintagma nominal con estructura $N+d e+N$ a aposición y/o composición cuando se siente dicho sintagma como una estructura fija, siguiendo un proceso de unión similar al que señala Martinell a propósito de los compuestos ortográficos: "hay una tendencia a la composición, que lleva del grupo sintagmático libre al sustantivo compuesto... Es posible hablar de una evolución que va del sintagma nominal libremente constituido al sustantivo compuesto ratificado por la unidad ortográfica"31. Y en lo que se refiere a los compuestos $N+d e+N$, la fijación entre sus miembros hace que en algunos casos pueda llegar a perderse la preposición, tal y como explica Gràcia: "observem que quam un sintagma $N$ de $N$ se sent com un compost (sináptic), de vegades la llengua col.loquial els converteix en compostos pròpiament dits i fa desaparèixer la preposició"32.

A propósito de la formación de compuestos nominales con dos nombres, sin la mediación de una preposición, Val Álvaro explica que la adjunción o yuxtaposición de

los compuestos nominales construidos con dos sustantivos presentan dos subtipos en los que se da distinta productividad y cohesión: en un caso, la concatenación de los nombres se produce libremente $(<\mathrm{N}+\mathrm{N}>)$; en el otro, se da mediante la existencia de una vocal de enlace $(<\mathrm{N}-\mathrm{i}+\mathrm{N}>)$ que fonológicamente forma parte del primer elemento. La formación de nombres mediante la unión de dos sustantivos sin vocal de enlace comprende dos modalidades: hay compuestos (perfectos) cuyos elementos están sólidamente fusionados formando una sola palabra fonológica y b) hay compuestos (imperfectos) que presentan dos componentes

30 Op. cit., p. 949.

31 "De la complementación a la composición en el sintagma nominal", REL, 14 (1984), pp. 224, 233.

32 Morfología léxica. L'herència de l'estructura argumental, Universitat, València, 1995, p. 62. 
que no han llegado a amalgamarse fonológicamente. Los primeros corresponden a tipos como aguamiel, sureste, zarzamora, a los que se asimilan compuestos que proceden de una composición sintagmática como telaraña. Los segundos incluyen tipos como los de café-teatro, fútbol-sala, hombre rana, buque hospital y hombre anuncio. Esta segunda modalidad constituye uno de los procedimientos más productivos y complejos de la composición en español ${ }^{33}$.

En aquellos casos en los que no hay vocal de enlace - que son la mayoría34-, el procedimiento que se sigue para la unión de los dos elementos que los forman hace que se puedan establecer varios grupos: $a$ ) los compuestos endocéntricos coordinativos (del tipo aguamiel, café teatro y suroeste); b) los compuestos endocéntricos subordinativos con primer elemento nuclear (del tipo telaraña, bocamanga, bocacalle, bocamina, camión cisterna, etc.), caracterizados por tener más vitalidad que $c$ ), que son los compuestos endocéntricos subordinativos con segundo nombre nuclear (como zarzamora, videoclub), precisamente porque el determinante no suele anteceder al núcleo ${ }^{35}$ : en estos dos grupos subordinativos hay una relación de modificación por la existencia de un elemento determinado y otro determinante; y d) los compuestos exocéntricos (del tipo ajoarriero, balompié, gallocresta, etc.). En todos ellos, a excepción, claro está, de los exocéntricos, se recurre a la correspondiente estructura sintagmática para explicar la relación que contraen sus miembros constituyentes; en los subordinados, a propósito de la posible existencia de una marca de rección, Val Álvaro señala que

la referencia a un determinado tipo de entidad viene dada-como ocurre en las construcciones sintácticas paralelas (tela de araña)-

${ }^{33}$ Art. cit., p. 4778.

34 Val Álvaro explica la escasez de la composición con vocal de enlace "por el número relativamente escaso de formaciones existentes y por el infrecuente uso de la mayoría de ellas, que es debido a la desaparición de los objetos que denominan (arquibanco, carricuba, catricofre), a su sustitución por otras (ajiaceite) e incluso al carácter regional de algunas". Sin embargo, "los compuestos de la forma $<\mathrm{N}-\mathrm{i}+\mathrm{N}>$ forman el tipo con mayor grado de integración morfológica y fonológica de la formación de sustantivos mediante la concatenación de dos nombres" (art. cit., p. 4787).

${ }^{35}$ Lo que se compadece bien con la posición que suelen ocupar los modificadores en una estructura sintagmática, a diferencia de lo que sucede en inglés, o en compuestos terminológicos con temas grecolatinos como radiopatía, fisioterapia o aerotecnia. 
por el primer elemento nominal. El segundo complementa al núcleo sin que medie rección entre ellos ${ }^{36}$; hay, pues, una relación de modificación del segundo constituyente al primero ${ }^{37}$.

Una situación similar para la unión de los elementos constituyentes es la que se da en los compuestos nominales de $\mathrm{V}+\mathrm{N}$, en los que la consideración del primer elemento del compuesto como verbo, por lo menos en su explicación diacrónica, permitiría asignar caso al nombre que lo complementa (precisamente porque no es nada desdeñable el hecho de que este grupo de compuestos se conozca como del tipo $\mathrm{V}+\mathrm{N}$ y no $\mathrm{N}+\mathrm{N}$ ); por otra parte, la estipulación de que dicho elemento no es una forma verbal, sino un nombre deverbal, como se postula en la actualidad, obligaría a la aparición de una marca de caso que favoreciera la unión entre las dos bases; claro que el problema que plantea la falta de esa marca de caso en la unión de dos nombres desaparece cuando se explica que un compuesto nominal es el resultado de un proceso morfológico - y no sintáctico-, razón por la cual no operan consideraciones sintácticas en la explicación de su estructura interna y, por tanto, no procede la aplicación de la teoría del caso. Sin embargo, hay que tener en cuenta que el tipo de compuesto $\mathrm{V}+\mathrm{N}$ es uno de los pocos tipos de compuestos nominales que pueden crearse, en el que no se produce la alteración fonológica de ninguna de las bases que intervienen en su formación para permitir su unión, y en el que el orden determinado-determinante, núcleo y complemento, se mantiene igual que en una estructura sintagmática correspondiente de verbo más nombre ${ }^{38}$. Por esta razón parece pertinente insistir en la existencia de un primer elemento verbal, por lo menos en su origen.

\section{LA NATURALEZA DEL PRIMER ELEMENTO DEL COMPUESTO DE V+N}

Las lenguas con una morfología derivativa productiva, como es el caso del español, suelen dejar bastante libertad a la hora de

36 Las cursivas son mías.

37 Art. cit., p. 4783.

38 De ahí la escasa productividad de compuestos $\mathrm{V}+\mathrm{N}$ en los que el segundo elemento no es objeto o tema del verbo, como reposacabezas, girasol, pasamontañas, etc. 
formar palabras compuestas: por ejemplo, camposanto o aguafiestas son palabras complejas que se originan al unir dos palabras independientes (con algunos matices en ciertos casos, como sucede en los compuestos que tratamos aquí, en los que el nombre deverbal que funciona como núcleo no suele aparecer aislado como palabra independiente, sí el verbo del que procede). Sin embargo, esta es la explicación que se ha dado tradicionalmente de la composición, lo que supone admitir que en su formación intervienen dos palabras independientes como base para la creación de una nueva palabra ${ }^{39}$, cuando, ciertamente, el problema reside en que, mientras en un compuesto como hombre rana o bocacalle podemos aislar dos nombres, hombre y rana y boca y calle respectivamente, en los compuestos nominales de verbo más nombre estamos obligados a decir $-\mathrm{y}$ prueba de ello es el tipo al que adscribimos estas formacionesque están integrados por un verbo y un nombre, algo que con toda probabilidad es el motivo que favorece el reconocimiento de su estructura por parte de los hablantes y lo que hace de este tipo de compuestos uno de los más productivos en la actualidad. Ese reconocimiento ha hecho, además, que la formación de este tipo de compuestos goce hoy de una gran vitalidad y productividad en español, lo que explica la atención recibida por parte de los investigadores, precisamente, porque no se compadece su productividad con la necesidad de considerarlos exocéntricos ${ }^{40}$. Sin embargo, el problema no está en señalar la

39 Pinker (op. cit., p. 138) simplifica y habla de dos 'palabras' independientes. Pena explica que "resulta más adecuado decir que la composición es un proceso morfológico en el que se añade una base a otra base y definimos base como aquel constituyente de la palabra, en cualquier nivel de constitución o estructura jerárquica, sobre el que puede operar un proceso morfológico" ("Partes de la morfología. Las unidades del análisis morfológico”, en Gramática descriptiva de la lengua española, t. 3, p. 4318).

${ }^{40}$ Entendiendo productividad como hacen PIERA y Varela: "cuando se dice que un esquema morfológico es productivo, en realidad se está dando nombre a la intuición que tiene el hablante de que es un esquema disponible para formar sobre él nuevas palabras, el cual, en caso de tener excepciones, está sometido a restricciones bien definidas" (art. cit., p. 4378). Por su parte, la relación entre exocentricidad y semántica lleva a decir que los compuestos exocéntricos se caracterizan por una falta de interpretación composicional de lo denotado a partir de sus elementos constituyentes. Claro que en el caso de los compuestos nominales $\mathrm{V}+\mathrm{N}$ hay que hacer una distinción entre los compuestos del tipo limpiabotas, abrelatas, sacacorchos y los del tipo cascarrabias, cantamañanas, y soplagaitas, lo que hace que la distinción endo- 
existencia de un elemento verbal como primer constituyente, lo que hace que haya una relación de determinado-determinante o subordinado-subordinante con rección del verbo sobre el nombre, sino en determinar cuál es la forma verbal que está presente en estos compuestos -imperativo, presente de indicativo, tema verbal o derivado verbal-41, lo que ha hecho que hayan surgido a lo largo de las últimas décadas diversas posturas para explicarlo. De cuál sea la naturaleza del primer elemento depende, como señala Val Álvaro, el tratamiento que se dé a otros aspectos del compuesto: "la solución dada a este primer problema determina en buena medida el modo de afrontar otros dos centrales: el significado del compuesto y el papel desempeñado por el segundo constituyente"42.

Una de las primeras explicaciones surgidas acerca de la naturaleza del primer elemento es la que lo considera un imperati-

centrismo/exocentrismo -atendiendo a lo semántico- se plantee como una gradación y no como una oposición. Por esta razón, no faltan autores que plantean la conveniencia de prescindir de la distinción exocéntrico/endocéntrico después de comprobar cómo ha sido tratado este problema: CoSERIU ("La formación de palabras desde el punto de vista del contenido. A propósito del tipo coupe-papier", Gramática, semántica, universales. Estudios de lingüistica funcional, Gredos, Madrid, 1978, p. 244), por ejemplo, señala que la endocentricidad concierne al significado y la exocentricidad al referente, lo que le lleva a decir que todos los compuestos son endocéntricos; Morera ("Sobre nombres compuestos con el formante -i-", RFLL, 1996, núm. 15, p. 168) plantea que esta distinción se basa en un punto de vista referencialista ya superado; y PENA ("La palabra: estructura y procesos morfológicos", Verba, 18, 1991, p. 93) concluye que no es una distinción lingüísticamente pertinente: se puede prescindir de la distinción entre compuestos endocéntricos y exocéntricos, a no ser que, como apunta Almela (op. cit., p. 144), sea definida con criterios lingüísticos.

${ }^{41}$ Hay opiniones que defienden la idea de un truncamiento o elipsis en estos compuestos. Morano MarTínez señala que "interrogarnos sobre la posible innovación formal -junto semántica- de estos mecanismos conlleva reconocer si truncamientos y elipsis suponen la creación de un significante distinto al de las formas plenas, generalmente compuestas, esto es, retomar el debate de la homonimia y de la polisemia" ("Sobre las clasificaciones de la neología. La reducción interna como procedimiento neológico", Interlingüistica, 9, 1998, p. 209). Y señala también: "recordemos que hay casos de cambio de género «la busca» $\mathrm{y}$ «el buscapersonas»; de estatuto morfosintáctico, «narco», morfema no autónomo, «narco» sustantivo; de categoría léxica, «okupa», sustantivo, mientras que el lexema homónimo integrante del compuesto parece tener una naturaleza verbal".

42 Art. cit., p. 4789. 
vo ${ }^{43}$; sin embargo, los problemas para admitir esta explicación están en la existencia de verbos en los que difieren las bases para presente e imperativo. Más razonable es la postura que defiende la existencia de la tercera persona del singular del presente de indicativo, como hacen, por ejemplo, Ynduráin, Rosenblat y Lang, sirviéndose de argumentos morfológicos y semánticos ${ }^{44}$. Sin embargo, esto llevaría a aceptar que el compuesto tiene las propiedades de una forma personal del verbo,

43 Esta idea es la que defienden Diez (Grammaire des langues romanes, A. Franck, Paris, 1874 [reimp. Slatkine-Laffitte, Genève-Marseille, 1973, pp. 405-407]) y MEYER-LüBKe (Grammaire des langues romanes II. Morphologie, Paris, 1894 [reimp. Slatkine-Laffitte, Genève-Marseille, 1974, § 547]), y centrado en el dominio del francés, DARMESTETER (Traité de la formation des mots composés dans la langue française comparée aux autres langues romanes, Paris, 1875 [reed. Honoré Champion, 1967, pp. 146-191]). Como señala VAL ÁLvARo "el objetivo de estos estudios no es tanto describir el comportamiento de estas voces cuanto explicar su origen y desarrollo. Dado que es un sistema de composición romance que se desarrolla a partir del siglo IX -con ejemplos aislados entre los siglos IV y VIII- el objetivo es dar cuenta de la génesis y evolución de esta estructura. Son, en este sentido, argumentos diacrónicos (interpretación de los primeros nombres que aparecen en las lenguas romances, especialmente en italiano y francés) los que justifican la propuesta" (art. cit., p. 4789).

44 YNDURÁIn, "Nótulas sobre la composición de verbo más nombre", Homenaje a José Manuel Pardo de Santayana y Suárez, comp. J. Albareda Piazuelo et al., Hogar Pignatelli, Zaragoza, 1963, p. 202 y "Sobre un tipo de composición nominal verbo+nombre", Presente y futuro de la lengua española, OFINES, Madrid, 1964, t. 2, p. 301; Rosenblat, "El género de los compuestos", NRFH, 7 (1953), p. 103 y LANG, op. cit., p. 106. Los argumentos para defenderlo son los siguientes, que resume VAL Álvaro (art. cit., p. 4789): a) el primer constituyente de estos compuestos es en general una forma de presente -temáticamente distinta del infinitivo, aunque puede ser homófona. Esto es manifiesto en ejemplos en los que difieren tema de infinitivo y de presente. Así sucede en las formas de primera y segunda conjugación con diptongación en sílaba tónica (cuentacuentos, cuentakilómetros, descuernapadrastros, desentierramuertos, desuellacaras, sueldacostilla, vierteaguas). También ocurre así en las formas regulares de la tercera conjugación (abrebotellas, cubrecama, cumpleaños, escurreplatos); b) estas formaciones son parafraseables por oraciones adjetivas de relativo (recogepelotas = persona que recoge pelotas); $c$ ) el aspecto habitual del presente de indicativo está en correlación con el plural gramatical que se da en la mayoría de los casos de sustantivo del compuesto (véase YNDURÁrn, "Sobre un tipo de composición nominal verbo+nombre", t. 2, p. 301). En efecto, el valor habitual que entraña el compuesto coincide con el del predicado en oraciones equivalentes con objeto directo en plural: Este médico sólo come verduras, Luis aparca coches. 
como ha señalado Contreras, lo que obligaría a incorporar un elemento equiparable al sujeto ${ }^{45}$.

Otra postura que analiza la naturaleza del primer elemento es la que lo considera un tema verbal, idea que defienden Alemany y con posterioridad, Marouzeau, Vañó-Cerdá y Bustos Gisbert ${ }^{46}$; pero, al igual que en las explicaciones anteriores, esta propuesta no da cuenta de cómo de una construcción verbo más nombre, en la que el nombre depende del verbo, resulta un compuesto con categoría nominal. Por esta razón, Val Álvaro concluye que "la categoría nominal de estos compuestos y la inexistencia aparente de un elemento nuclear que atribuya esa categoría dan lugar a propuestas que tratan de explicar por qué son sustantivos e interpretar el compuesto como una construcción endocéntrica" 47 ; asunto éste del endocentrismo que ha determinado el rumbo que han tomado todas estas explicaciones acerca de la naturaleza del primer elemento del compuesto. Así, después de examinar las distintas opiniones y posturas ofrecidas para explicar la naturaleza del primer ele-

${ }^{45}$ En "Spanish exocentric compounds", Current issues in Hispanic phonology and morphology, ed. F. H. Nuessel, IULC, Bloomington, 1985, p. 17. Las razones que se esgrimen en contra de esta explicación son las siguientes: a) una solución como la de CONTRERAs (pp. 14-27) no permite dar cuenta de que $\mathrm{V}$ ha de aparecer siempre en tercera persona del singular y va seguida de un sustantivo objeto, aparte de que esta representación haría posible generar construcciones nominales agramaticales como *el tocadiscos por la gramola; $b$ ) hay casos en que cabe proponer nombres sin realización fónica en un $\mathrm{SN}$, pero no se trata de un nombre necesariamente vacío. En construcciones con referencia anafórica a un elemento del texto, éste transmite información, entre otros aspectos, sobre el género (el agua ${ }_{i}$ clara y la $N_{i}$ sucia). Cuando la referencia viene dada por el contexto comunicativo, el nombre del objeto señalado aporta la información ([Mostrando una moneda enorme] -Te traigo $N$ más grande). En ausencia de referencia, se selecciona la denotación de personas y la referencia genérica se realiza en masculino (Todos, los buenos y los malos, tienen defectos). La solución propuesta no establece cómo el nombre vacío adquiere -si la lleva- esta información, que es relevante, por ejemplo, para la concordancia con el artículo dentro del sintagma nominal. Por defecto, el género seleccionado en estos compuestos es masculino, y es casi general en la denominación de objetos.

46 Véanse Alemany, Tratado de la formación de palabras en la lengua castellana, Victoriano Suárez, Madrid, 1920, p. 169; Marouzeau, "Composés à thème verbal”, FrM, 20 (1952), p. 86; VAÑó-CERDÁ, "Sobre el tipo de composición romance "porta-plumas'”, Caligrama, 1 (1984), p. 187 y Bustos GisBert, La composición nominal en español, Universidad, Salamanca, 1986, p. 258.

47 Art. cit., p. 4791. 
mento del compuesto del tipo limpiabotas, se ha llegado a la conclusión, como hacen Varela ${ }^{48}$, desarrollando la propuesta de Coseriu, y, a partir de ahí, otros estudiosos, de que el primer elemento del compuesto es un nombre deverbal que funciona como núcleo capaz de transmitir sus rasgos categoriales a la totalidad del compuesto.

A esto se une el problema de determinar el papel del segundo constituyente en la estructura del compuesto. La tradición gramatical, los estudios estructuralistas y generativistas hasta la hipótesis lexicalista han relacionado estos compuestos con construcciones sintácticas, cuyo núcleo verbal fuera idéntico al primer elemento de estas voces compuestas. Ello ha favorecido la consideración del segundo elemento como objeto directo o tema, de acuerdo con la estructura argumental que desarrolla el verbo ${ }^{49}$. Así, como señalan Piera y Varela

al igual que en sintaxis, en ciertas estructuras léxicas la posición de un determinado constituyente puede resultar una marca crucial para identificar la relación de dependencia que establece tal constituyente con otro de la misma palabra. Así, por ejemplo, en los compuestos deverbales del tipo cubrecama, el segundo constituyente puede ser identificado como complemento del primero simplemente por la posición que ocupa, pues no hay otra marca de función -caso o preposición, por ejemplo-que refleje esta dependencia. La simple posición inmediata al núcleo (cubre) identifica al complemento $(\mathrm{cama})^{50}$.

Lo que no sucede en otro tipo de compuestos nominales, en particular, en los llamados "radicales" o "primarios" - como aguamanos, aguanieve-, en cuyo interior las conexiones semánticas son menos transparentes que en sintaxis, y que en los

${ }^{48}$ S. VARELA, "Condicionamientos sintácticos en procesos morfológicos de afijación y composición”, en Estudios de Lingüística de España y México, eds. V. Demonte, y B. Garza, UNAM-El Colegio de México, México, 1990, pp. 95-114; y "Composición nominal y estructura temática", REL, 20 (1990), 55-81, desarrollando la propuesta de Coseriu (art. cit.).

${ }^{49} \mathrm{Si}$ bien existen casos en los que el sustantivo no es el objeto o tema, sino el sujeto, el circunstancial o incluso el complemento preposicional, como se observa en los siguientes ejemplos: girasol, reposacabezas, saltamontes, pasamontaña, guardalodos, gardabarros, gardapolvo, guardacantón, etc.

${ }^{50}$ Art. cit., p. 4374. 
compuestos "sintéticos" o "deverbales", por la falta de elementos de relación como la preposición y el caso.

\section{5. ¿EXISTE ASIGNACIÓN Y MARCA DE CASO EN EL INTERIOR DEL COMPUESTO?}

El reconocimiento de un núcleo deverbal (derivado verbal o nombre deverbal) con afijo o morfo cero ${ }^{51}$ que permite su consideración como endocéntrico y, por tanto, la existencia de un núcleo nominal que proyecta sus rasgos categoriales a la totalidad del compuesto mediante el filtrado de rasgos, lleva a plantear cómo se produce la adición del sustantivo al nombre deverbal, toda vez que un nombre (derivado) no puede asignar caso a su complemento. La comparación de estos compuestos nominales con nombre deverbal y afijo cero como núcleo, con la correspondiente estructura con sufijo agentivo realizado formalmente en el afijo -dor, conduce a Gràcia a explicar que

Vist que els compostos del tipus parallamps són molt similars, en sentit i en estructura, als de (51) [vendedor de sabates, reproductor de microfilms], sembla que analitzar-los com proposa Varela $(48)^{52} \mathrm{i}$ com proposem nosaltres (52) ${ }^{53}$ dóna compte d'aquestes simili-

${ }^{51}$ LANG (op. cit., p. 35) señala que la derivación regresiva, también llamada sufijación cero, es un procedimiento muy frecuente en los nombres deverbales, como los que estudiamos aquí.

${ }^{52}$ La estructura de (48) es la siguiente:
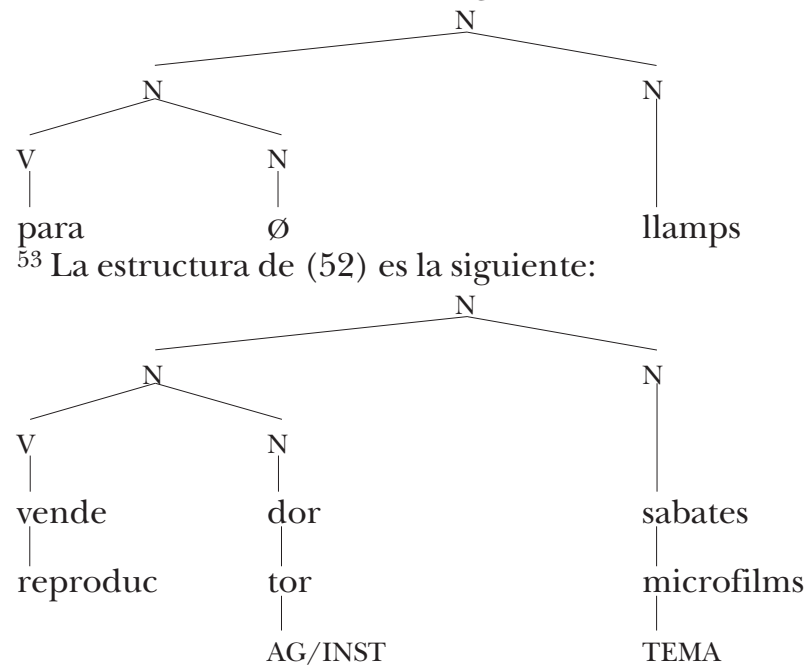
tuds. L'única diferència és la tria del sufix agentiu, zero en el primer cas i -dor en el segon. El fet que una arrel verbal triï un afix o en triï un altre sembla que és força aleatori, potser l'única restricció als compostos amb afix zero és que l'arrel ha de pertànyer, preferentment, a la primera conjugació. El que s'hauria d'explicar, però, és l'aparició de la preposició de quan el primer element té el sufix-dor i l'absència de preposició quan el sufijo és zero ${ }^{54}$;

lo que la obliga a preguntarse por qué aparece la preposición en los segundos ejemplos y no en los primeros. De un modo exhaustivo -que reproduzco a continuación-, comparando los dos tipos de compuestos nominales, uno en el que el resultado es un compuesto formado por una sola palabra, y otro en el que aparece una estructura compleja, formalmente similar al sintagma nominal, Gràcia señala lo siguiente:

els lingüistes que analitzaven els compostos del tipus parallamps com a elements formats per una arrel verbal seguida d'una de nominal, evidentment, no se plantejaven la qüestió de la preposició. L'element nominal corresponia a l'objete verbal i, com a tal, no tenia preposició. En el moment en què assumim que el primer element és un nom derivat d'un verb, ens hem de preguntar per què el segon element, l'objecte, no està introduït per una preposició. I la pregunta encara és més obligada si, com hem fet nosaltres, suposem qui ha un paral.lelisme molt estret entre aquests compostos i els nominals no eventius del tipus recol.lectora de blat, que també hem analitzat com a compostos. Més concretament, la pregunta seria: si totes dues formacions són mots compostos amb un primer element nominal agentiu (o instrumental), per què en un cas hi ha preposió i en l'altre no? És a dir, per qué les estructures de (53) a. parallamps, b. recol.lectora de blat són gramaticals i les (54) a. *paradellamps, b. *recol.lectora blat no.

Sembla que l'opció meys marcada és que hi hagi la preposició, de la mateixa manera que hi és en casos com blat de moro o moli de vent. Si el primer element és un nom, el segon ha de portar preposició per a rebre Cas. Quan el sufix és -dor, l'arrel verbal es converteix en nom i, por tant, la peça resultant no pot assignar Cas; podríem dir que el sufix l'ha absorbit. En aquesta línia podríem suposar que un sufix fonològicament buit no pot absorbir el Cas; el nom resultant, doncs, tindria capacitat per a assignarne al segon element del compost. Això, però, no explicaria per què els noms deverbals amb sufix zero, como rebuig o record han d'in-

54 Op. cit., p. 60. Las cursivas son mías. 
troduir el complement obligatòriament amb la preposició 55 : (55) a. el $\left[[\text { record }]_{\mathrm{V}} 0\right]_{\mathrm{N}} *\left(\right.$ de) la casa; b. el $\left[[\text { para }]_{\mathrm{V}} 0\right]_{\mathrm{N}}(*$ de $)$ llamps $]$. El sufix zero de (55a) no està lligat a cap argument i el de (55b) sí, però això no sembla que tingui res a veure amb el problema de la preposició. La qüestió més aviat s'hauria de relacionar amb el fet que (55a) és una construcció sintàctica i (55b) és una formació morfològica. Però si el fet de ser una construcció morfològica és el que permet que el complement d'un nom aparegui sense preposició, hem de suposar que és perquè el Filtre de Cas no és pertinent per a la morfologia. Aleshores no s'explica per què quan el primer element del compost és un nom amb el sufijo -dor el complement ha d'aparèixer amb preposició.

Notem que, encara que restringim el Filtre de Cas als SN, no resolem el problema, perquè encap dels dos tipus de compostos que estem analitzantno tenim SN como a segon element. En tots dos casos tenim un nom, igual que en els noms com moli de vent $\mathrm{o}$ blat de moro 56 .

Para explicar esta situación la autora recurre a la distinción entre compuestos propiamente dichos y compuestos sinápticos, según la terminología de Benveniste, creados a partir de una sintagma nominal ${ }^{57}$, y explica que

és possible que la soluciò a aquest problema s'hagi de relacionar amb el fet que es tracta de compostos de tipus diferent: parallamps seria un compost própiament dit, i, en canvi, les construccions en què apareix la preposició serien casos de sinapsi, que,

55 En español tendríamos estructuras similares, si existieran, en ejemplos como la toma de la casa, el tomacasas.

${ }^{56}$ Op. cit., pp. 60-61.

57 Véase Benveniste, "Formas nuevas de la composición nominal", Problemas de lingüistica general II, Siglo XXI, México, 1977 [1966], p. 172. Benveniste explica que hay un tipo de composición que, no reconocido todavía en su naturaleza propia, carece de estatuto definido: "consiste en un grupo entero de lexemas, ligados por diversos procedimientos y que forma una designación constante y específica... El hecho nuevo e importante es que adquiere hoy en día una extensión considerable y está llamado a una productividad indefinida: es y será la formación básica en las nomenclaturas técnicas... Para designar estas grandes unidades y para consagrar el fenómeno específico que representan se hace necesario un término nuevo, distinto de «composición» (precisamente se trata de algo que no es composición), distinto también de «sintagma», para dejar a sintagma su designación propia, que se aplica a no importa qué grupo, aun ocasional, operado por medios sintácticos, en tanto que aquí tenemos una unidad fija. Proponemos con este fin un término que parece adecuado y claro: Sinapsia" (p. 173). 
com diu Benveniste (1966: 172), es caracteritzen per "la nature syntaxique (non morphologique) de la liaison estre les membres". En aquest sentit serien "compostos" semblants a moli de vent o tauleta de nit. Es podria pensar que són mots compostos que s'han format per una lexicalització d'un sintagma, i això explicaria l'aparició de la preposició: una marca de cas, reminiscència de l'origen sintagmàtic del compost (p. 61).

Sin embargo, no parece que la explicación al problema que se deriva de la falta de una marca de caso esté en relacionar varios tipos de compuestos, y en explicar que los compuestos sintagmáticos o sinápticos (del tipo $N+d e+N$ ) proceden de un sintagma nominal lexicalizado en el que los dos nombres aparecen unidos por la preposición $d e$, sino en el hecho de que el compuesto nominal $\mathrm{V}+\mathrm{N}$, una vez formado, es una estructura morfológica y no sintáctica y, por tanto, son las reglas morfológicas, y no las sintácticas, las que tienen que estudiarlo. Esto equivaldría a decir que el filtro de caso no opera en morfología, conclusión poco satisfactoria como señala la autora, porque los compuestos sintagmáticos también son estructuras morfológicas, y por tanto, tampoco sería necesaria la preposición; pero si en este tipo de formaciones complejas aparece la marca de caso, y tal hecho se explica por su origen sintáctico, también debería aparecer la marca de caso en los compuestos de $\mathrm{V}+\mathrm{N}$; si la razón que explica la presencia de la preposición en los compuestos sintagmáticos es el proceso de lexicalización de un sintagma nominal previo en el que sí es obligatoria la marca de caso, lo mismo podría decirse de los compuestos del tipo $\mathrm{V}+\mathrm{N}$ que tienen su origen en una estructura sintagmática verbal en la que el núcleo verbal, capaz de asignar caso, selecciona como argumento interno al nombre que lo complementa y es la flexión verbal la que originariamente marca el caso. De este modo, las razones diacrónicas que justifican la presencia de la preposición en los compuestos sinápticos, serían aplicables también a los compuestos de $\mathrm{V}+\mathrm{N}$ para explicar el origen verbal del primer elemento y su consiguiente inserción en una tipología de compuestos de verbo+nombre y no de nombre+nombre. Esa marca de caso es la misma que justifica la preposición, por razones diacrónicas, en compuestos, hoy poco productivos, como montambanco, satambanco, saltaembanco, saltaembarca, tentempié, tentenelaire, tanto en un grupo como en otro estamos ante compuestos que han experimentado, en pri- 
mer lugar, un proceso de yuxtaposición - analizado por la sintaxis-, como explica Pena, para, a continuación, convertirse en compuestos - analizables por la morfología:

surgen inicialmente como yutaxposición, no como composición; es decir, se trata de formaciones no creadas directamente por composición, sino generadas por procedimientos sintácticos que, diacrónicamente, devienen en palabras al descender en el rango de unidades de la unidad frase a la unidad palabra. Se trata siempre de un proceso diacrónico según del cual una secuencia, que empieza por ser generada sintácticamente, con el tiempo deja de serlo y pasa a reanalizarse como palabra con sus consiguientes propiedades formales: imposibilidad de insertar, sustraer o permutar en sus constituyentes ${ }^{58}$.

Esa ausencia de una marca de caso en los compuestos nominales resultantes se debe a la existencia originaria de un elemento verbal que marca caso y que hace que el nombre deverbal herede sus propiedades lexico-semánticas (para recibir, por ejemplo, un complemento con papel temático de tema); por el contrario, si consideramos que es un compuesto nominal $N+N$, susceptible de ser tratado como un átomo sintáctico en el que no se puede alterar la constitución de sus elementos y no procede aplicar principios sintácticos, la falta de caso habría que explicarla del mismo modo que en compuestos como zarzamora o aguamiel. Pero lo importante es que ese primer constituyente tiene origen verbal y la facultad de asignar caso y por tanto no necesita ninguna preposición para efectuar la unión -razón por la cual este tipo de compuestos se estudia como perteneciente al tipo $\mathrm{V}+\mathrm{N}$ y no al de $\mathrm{N}+\mathrm{N}$. Esto explica que, por lo general, sólo aparezca el complemento directo o tema como segundo elemento del compuesto y no otro complemento del verbo, que sí obligaría a la presencia de una preposición. Esta situación la explica Varela, recurriendo, precisamente, a la teoría del caso, del siguiente modo:

el hecho de que no se adjunten en los compuestos elementos con otros posibles papeles-q (Locativo, Destinatario, Origen) podría explicarse apelando a la 'teoría del caso' (vid. Chomsky, 1981). En español peninsular, p. e., ha aparecido recientemente

58 J. PENA, “La palabra: estructura y procesos morfológicos”, p. 86. 
el compuesto cuentacuentos, como denominación de un aparato que contiene cintas magnetofónicas en las que están grabados cuentos infantiles, pero sería impensable que se formara un N-compuesto como *cuentacuentosniños en el sentido de 'lo que cuenta cuentos a los niños'. En el primer caso, en efecto, el primer argumento "cuentos" está temáticamente identificado por su posición adyacente al ND; en el segundo, el argumento "niños", no adyacente al núcleo, tendría que recibir caso de una preposición como en la variante oracional, que hiciera transparente su relación semántica con el núcleo. Como el español no permite la aparición de preposiciones asignadoras de caso en el interior de una categoría $\mathrm{X}^{\mathrm{o}}$ (salvo en formaciones ya no productivas del tipo tentempiê), ni la de unidades con caso morfológico (salvo, de nuevo, en casos marginales: correveidile), los ejemplos como el anterior no pueden resultar aceptables ${ }^{59}$.

Hay, no obstante, otra razón que haría innecesaria la presencia de la marca de caso, si se ofrece una interpretación sincrónica, y es la fusión que experimentan en una unidad fonológica las dos bases para formar el compuesto, igualando los compuestos del tipo limpiabotas con los de zarzamora, aguamiel, etc. Sin embargo, esta idea no está libre de problemas porque no dejan de existir peculiaridades en el comportamiento morfológico del primer constituyente del compuesto del tipo limpiabotas: efectivamente la consideración de un nombre deverbal como núcleo sirve para regularizar una situación particular en la que se encuentra este tipo de compuestos (entre otros motivos, por la inconveniencia de tenerlos que considerar exocéntricos); pero al adoptar esta postura defensora del nombre deverbal, sin hacer el suficiente hincapié en su origen verbal, falla la aplicación de la teoría del caso, cuando resulta que la idea de que el primer elemento del compuesto sea originariamente un verbo, recategorizado como nombre deverbal - como admiten en la actualidad todos los investigadores-, encuentra una explicación en la particularidad de su inexistencia como palabra aislada (aunque puede aparecer en algunos casos aislados tales como el busca, el cumple, el ocupa, el pincha, etc. ${ }^{60}$ ) y en que no tenga plena autonomía como palabra inde-

59 S. VARELA, Fundamentos de morfología, p. 113.

${ }^{60}$ A pesar de que Piera y Varela señalan que la aceptación del complemento o modificador no es opcional sino obligatoria: "los núcleos morfológicos, a diferencia de los sintagmáticos, tienen que seleccionar obligatoriamente un 
pendiente para experimentar cualquier cambio susceptible de la aplicación de procesos morfológicos, como la derivación, en particular, la sufijación apreciativa: de ahí que resulten extraños procesos como busca $\longrightarrow$ *busquita, ocupa $\longrightarrow$ *ocupita o liga $\longrightarrow$ ? liguita $^{61}$ (aunque existen formas derivadas como liguero), etc., en contraste con la productividad que tiene el uso de la sufijación apreciativa en cualquier otro tipo de nombres no deverbales, distintos a los que se postulan aquí para explicar la situación particular de estos compuestos nominales ${ }^{62}$.

complemento: -ción,-dad, por ejemplo, tienen que proyectar en la estructura léxica el complemento seleccionado, como en casación y bondad, respectivamente. Igualmente, en el caso de los compuestos, la aceptación del complemento o del modificador no es opcional sino obligatoria; cf. la diferencia entre calienta (los pies)SN y calienta*(pies)N", art. cit., p. 4376, n. 12. Más adelante al explicar la selección semántica de estos compuestos señalan que formas como *el lava por el lavaplatos son deficitarias, dada la necesidad de que el núcleo tenga cubierta su estructura argumental lo que hace necesario que aparezca el argumento seleccionado u obligatorio platos. Formas como el busca, el ocupa, etc., son explicadas, por tanto, como casos de acortamiento léxico en los que aparece preservado el núcleo predicativo.

${ }^{61}$ La extrañeza de este tipo de diminutivos tiene relación con la idea, señalada por LÁzAro Mora, de que "el difícil problema de la compatibilidad entre lexemas nominales y sufijos diminutivos se conoce aún de manera muy insuficiente, pese a que el análisis componencial y categorial de los significados se halla en una situación que permite abordar el problema con ciertas garantías. Posiblemente una de las mayores dificultades con que tropezamos sea la falta de un criterio seguro que permita decidir, sin vacilaciones, sobre la aceptabilidad o no de ciertas construcciones" ("La derivación apreciativa”, Gramática descriptiva de la lengua española, t. 3, p. 4651). Dentro de los casos de incompatibilidad para el uso del diminutivo están las profesiones o actividades con el sufijo -ista: periodista, accionista.

${ }^{62}$ Con excepción de los grupos que señala Lázaro Mora (art. cit., p. 4652). Precisamente, como apunta VAL ÁlvARO (art. cit., p. 4783), la creación de diminutivos y neologismos en voces como telarañita (telaraña) y chequetrentista (chequetrén) sirve para avalar el éxito de la formación de estos compuestos nominales, aunque no dejan de existir otros casos problemáticos que llevan a Lázaro Mora a decir que "el comportamiento de los sufijos diminutivos con los nombres compuestos tampoco ha sido estudiado con detalle, a pesar de que presentan problemas interesantes que requieren ser dilucidados". Es aceptable paragüitas (> paraguas) pero no *parachoquecitos (> parachoques), lo que se debe al hecho de que "el grado de fusión que el hablante percibe entre los formantes de un compuesto tiene una importancia decisiva en la configuración de los derivados diminutivos... Mientras que paragüitas es posible interpretarlo como «paraguas pequeño», o teñirlo de afecto, *parachoquecitos difícilmente admitiría esas interpretaciones. Es la distinta cohesión entre los formantes la que determina la formación de 
La conclusión que se deriva de lo expuesto en los apartados anteriores es que la interpretación que hay que dar a los compuestos nominales de verbo+nombre tiene que pasar por reconocer que el origen para la formación de este tipo de palabras complejas está en el mantenimiento de la estructura verbo más complemento. Sólo así se puede explicar que no haya necesidad de marcar caso; de lo contrario, si no admitiésemos la existencia de este esquema sintagmático para favorecer la formación de estos compuestos nominales, habría que considerarlos como un caso particular en el que la existencia del nombre deverbal habría permitido la unión de ambos nombres sin la presencia de una preposición, de manera similar a como sucede en otro tipo de compuestos nominales $\mathrm{N}+\mathrm{N}$, con menos productividad que los de la estructura $\mathrm{V}+\mathrm{N}$, y en los que, a excepción de los coordinativos, reflejan también dependencias similares a las que se dan en una estructura sintagmática. Sin embargo, la existencia de algunas formaciones - hoy ya no productivas- dotadas de preposición asignadora de caso (como tentempié, tentenelaire, sataembanco, etc.), hacen pensar en la existencia de un primer elemento verbal, lo que razonablemente puede ser aplicado al resto de compuestos nominales de $\mathrm{V}+\mathrm{N}$ y explicar, por lo tanto, la adyacencia del segundo elemento como resultado de la marcación del caso que le asigna el verbo (del mismo modo que en el compuesto lector de microfichas, la presencia de la preposición de es reflejo de su origen sintagmático, aunque hoy esa estructura es analizada por principios estrictamente morfológicos).

Por último, en favor del mantenimiento del origen verbal del primer elemento de estos compuestos, hay que señalar que la explicación de dicho constituyente como un nombre deverbal surge con posterioridad a la formación de este tipo de compuestos, con el objeto de regularizar la situación excepcional

posibles derivados diminutivos" (p. 4653). La conclusión parece estar en que las palabras compuestas -y más aún éstas que han experimentado un proceso de acortamiento- son reacias a presentarse con sufijos apreciativos. A lo que se puede unir el rechazo de la mayoría de los sustantivos masculinos terminados en - $a$ (como sería el limpia, el busca, el ocupa, etc.) para presentar diminutivo. 
que supondría tenerlos que considerar exocéntricos; una prueba de que el nombre deverbal no es anterior a la creación del compuesto por parte de los hablantes, la tenemos en el escaso rendimiento que tienen estos nombres deverbales para ser utilizados con independencia, como palabra aislada, fuera del compuesto, como revela, por ejemplo, la aplicación de la morfología apreciativa.

ENRIQUE JIMÉNEZ RÍOS Universidad de Salamanca 